\title{
ELOGIO DE LA CIUDAD. SEMBLANZA DE LA FILOSOFÍA COMO FENÓMENO URBANO ${ }^{1}$
}

\author{
EULOGY OF THE CITY. SKETCH OF PHILOSOPHY AS URBAN PHENOMENON
}

\author{
Luis Durán Guerra ${ }^{2}$ \\ Universidad de Sevilla (España)
}

Recibido: 01-05-2014

Aceptado: 16-06-2014

\begin{abstract}
Resumen: En este trabajo se realiza una caracterización de la filosofía como una actividad cultural que no se puede separar del espacio urbano. Se explica el desinterés de los filósofos por la ciudad apelando a su negativa a reconocer el fenómeno urbano como un elemento esencial de la naturaleza humana. La tesis central es que, fuera de la ciudad, no hay lugar para la filosofía.
\end{abstract}

Palabras-clave: ciudad, filosofía, urbs, civitas, ciudadano.

\begin{abstract}
This paper is carried out a characterization of philosophy as a cultural activity which cannot be separated from the urban space. The lack of interest of the philosophers by the city is explained appealing to its refusal to recognize the urban phenomenon as an essential element of human nature. The central thesis is that, outside of town, no place for philosophy.
\end{abstract}

Key-words: city, philosophy, urbs, civitas, citizen.

[1] Una versión notablemente más abreviada de este trabajo fue presentada por mí como ponencia en el III Congreso Internacional para jóvenes Diálogos. La relación entre Filosofía y mundo contemporáneo, 31 de enero y 1 de febrero de 2014 (Universidad de Navarra).

[2] (lduran@aafi.es) Licenciado en Filosofía por la Universidad de Sevilla, obtiene el D.E.A. (Diploma de Estudios Avanzados) por la misma Universidad en 2009. Su Trabajo de Investigación estuvo consagrado a la figura de Hans Blumenberg. Ha publicado varios artículos y reseñas en revistas como Cuadernos sobre Vico, Revista de Filosofía, Alfa, Erebea, El Catoblepas, etc. Ganador del VI Certamen de Ensayo Brevísimo Oliva Sabuco, ha obtenido recientemente el primer accésit del I Premio Hispanoamericano de Ensayo Filosófico Nódulo Materialista (2013). Es miembro de la Asociación Andaluza de Filosofía desde 2012 y Asistente Honorario del profesor Dr. José Antonio Marín Casanova (Universidad de Sevilla). 
Los pueblos, los Estados, la política, la religión, todas las artes, todas las ciencias, se fundan en un único protofenómeno de la existencia humana; en la ciudad. Pero todos los pensadores de todas las culturas viven en ciudades, aunque su cuerpo se encuentre en el campo; por eso no saben cuán extraña cosa es la ciudad.

O. Spengler, La decadencia de Occidente, II, 2.

Es muy curioso que se incline uno a pensar que la civilización -las casas, las calles, los automóviles, etc.- aleja a los hombres de su origen, de lo alto, infinito y demás. Parecerá entonces que el ambiente civilizado, incluso los árboles y las plantas que hay en él, estuviera adecuadamente envuelto en celofán y aislado de todo lo grande y, por así decirlo, de Dios. La que se presenta es una imagen curiosa.

L. Wittgenstein, Aforismos.

El objetivo principal de este trabajo consiste en justificar documentalmente cómo la filosofía se vincula necesariamente con la ciudad. Aunque existe una amplia bibliografía especializada sobre la ciudad, no se puede decir que la relación entre filosofía y ciudad haya sido tratada extensamente. Entre los estudios más cercanos a nuestro ámbito cultural dedicados al tema citaré aquí, sin ánimo de exhaustividad, el libro editado por Carlos Alberto Torres Tovar, Fernando Viviescas Monsalve y Edmundo Pérez Hernández, La ciudad: hábitat de diversidad y complejidad (Bogotá, Universidad Nacional de Colombia, 2000), el cual incluye un interesante artículo de Bernardo Correa López bajo el título "La ciudad en la reflexión filosófica" (pp. 64-71), los dos volúmenes a cargo de la profesora de la Universidad de Oporto Paula Cristina Pereira, A Filosofia e a Cidade (Porto, Campo das Letras, 2008 y Porto, Edições Afrontamento, 2010) y el número extraordinario (52, noviembre 2013) dedicado al estudio de las ciudades contemporáneas de la revista española Eikasía, coordinado por los profesores Armando Menéndez Viso y Francisco Javier Gil Martín, etc. Por lo demás, una buena antología de textos clásicos y contemporáneos sobre filosofía y ciudad se encuentra en el libro editado por Sharon M. Meagher, Philosophy and the City: Classic to Contemporary Writings (Albany, State University of New York Press, 2008). No se trata, pues, de un argumento nuevo, si bien me temo que no goce de una gran repercusión. Aún así, la actualidad del tema está fuera de toda duda. Las páginas que siguen quisieran contribuir, desde una perspectiva laudatoria, al esclarecimiento del binomio filosofía-ciudad, pues el autor está convencido de que la filosofía surge y va unida al fenómeno del urbanismo.

En el primer apartado, explico la tradicional enemiga de los filósofos contra la ciudad sobre la base de su negativa a ver el fenómeno urbano como un componente esencial de la naturaleza humana. A continuación, comento el texto de Heidegger ¿̇Por qué permanecemos en la provincia? como un ejemplo 
de la oposición errónea ciudad/campo que articula buena parte de los discursos sobre el argumento de este ensayo. En un tercer apartado, presento la ciudad como una "metáfora absoluta" en el sentido que Hans Blumenberg ha otorgado a esta expresión. En el cuarto apartado, destaco la diferencia esencial entre urbs y civitas, caracterizo los tipos básicos de ciudades y sostengo la tesis de que la diferencia entre los sistemas filosóficos acaso pueda ilustrarse por la urbanística y la arquitectura. A continuación, realizo algunas consideraciones sobre el origen de la ciudad comentado los ejemplos contrapuestos de la Biblia y de la fundación de Roma. El sexto apartado incide sobre el problema de la definición de ciudad para terminar con unos apuntes sobre la necesidad de pensar nuestra ciudadanía contemporánea en la ciudad cosmopolita de nuestro tiempo. Finalmente, en la conclusión, el autor aboga no tanto por una teoría filosófica de la ciudad como por devolver a las filosofías al lugar que constituye su única condición histórica de posibilidad y realidad.

\section{La filosofía y la ciudad}

El paso del mito al lógos no se habría dado nunca sin aquel otro que va de polis a physis como nacimiento de la filosofía de la naturaleza desde el espíritu de la ciudad-estado. Histórica y culturalmente, la aparición del filósofo es inseparable del desarrollo de los grandes emporios de la civilización occidental. Mileto, con su puerto comercial, fue la cuna de la especulación cosmológica de los presocráticos; en el ágora de Atenas se produjo el giro antropológico del pensamiento protagonizado por Sócrates y los sofistas; Alejandría albergó la más famosa biblioteca de la Antigüedad y un Museo para fomentar la investigación científica. La Córdoba califal fue un oasis de civilidad en medio de la oscuridad de los villorrios del Medioevo. El Renacimiento italiano está ligado al florecimiento cultural y económico de ciudades como Florencia. Sobre el eje París-Berlín-Londres se ha gestado lo más granado de la cultura europea contemporánea. Urbanidad y policía no salieron nunca de los silencios del bosque, sólo terror pánico y superstición de lo numinoso. La ciudad es el mundo del hombre, un espacio humanizado para la filosofía y el arte frente a la naturaleza inculta y la barbarie de los campos. Encrucijada de caminos, crisol de posibilidades para la humana creatividad, la ciudad es sinónimo de ocio y de negocio, de goce y de movilidad social, de esplendor y miseria. Si el entramado de calles y edificios, con sus organismos públicos y centros comerciales, plazas, monumentos y mobiliario urbano, constituye el ecosistema cultural donde de hecho vivimos, ¿cómo se explica entonces el presunto desinterés de los grandes pensadores por el fenómeno urbano como tal? Es más, ¿cómo entender, en ciertos casos señalados, su predilección por la soledad y el retiramiento en la aldea o en el camino de campo? 
La respuesta a esta pregunta no puede ser otra que la negativa de toda una tradición filosófica a reconocer el fenómeno urbano como un elemento esencial de la naturaleza humana. Con diversos matices, cínicos, epicúreos y neoplatónicos coincidieron ya en la Antigüedad en su crítica cultural de la ciudad. Si Diógenes vivía cínicamente en un tonel y el lema del jardín de Epicuro fue "vive oculto", Plotino pudo comparar la vida urbana con el teatro para destacar quizá su carácter ilusorio o meramente accidental: "los asesinatos, las matanzas, el asalto y saqueo de las ciudades... todo ello debemos considerarlo con los mismos ojos con que en el teatro vemos los cambios de escena, las mudanzas de los personajes, los llantos y gritos de los actores». ${ }^{3}$ Para el estoico Epicteto, más valía vivir como hombre sabio en una humilde cabaña que como necio en un soberbio palacio. El cristianismo se suma a esta tradición antigua de menosprecio de la ciudad. Bastará recordar aquí, a pesar de su entrada triunfal, el significativo lamento de Jesús ante Jerusalén o las no menos dramáticas imprecaciones que narran los evangelios sobre aquellas otras ciudades impenitentes que permanecieron insensibles a los milagros. Para San Agustín, la patria verdadera del hombre es la ciudad celestial, la Iglesia, que él contrapone en su De civitate Dei a la ciudad terrenal, simbolizada por Babilonia o Roma. La protesta de Lutero se originó en la indignación que suscitó en su rústica alma de campesino la Roma papista. Y si bien la vocación cívica del humanismo es incompatible con el retiramiento, la tendencia a éste marca el final del proyecto cultural del humanismo como se preanuncia ya en la obra de Guevara Menosprecio de corte y alabanza de aldea (1539), por mencionar el texto más conocido sobre este tema en la cultura española. Después llegó Rousseau y su nefasta -por mal entendida- "vuelta a la naturaleza", la cual no habría pasado de ser una ensoñación romántica del paseante solitario si no hubiera tenido como corolario un virulento ataque a la civilización como origen de todas las calamidades que aquejan al ser humano. Durante mucho tiempo se ha identificado la ciudad con el mal, la enfermedad y el vicio en oposición a las bondades de la vida rural y campesina. Esta corriente llega hasta nuestros días con el predicamento del ecologismo y la preferencia por la ruralidad entre los cansados del mundanal ruido de nuestras grandes ciudades y los amantes de la calma de la descansada vida. Parecería entonces como si el ambiente de la civilización urbana nos alejase, como dice Wittgenstein, «de todo lo grande, y por así decirlo, de Dios». ${ }^{4}$ Esta imagen que a Wittgenstein sólo le parece curiosa, en realidad no es más que una bobada.

[3] Enn., II, 2, 9.

[4] L. Wittgenstein, Aforismos. Cultura y valor, Espasa Calpe, Madrid, 1996, § 281, pp. 101-102.

THÉMATA. Revista de Filosofía, Nº51 enero-junio (2015) pp.: 145-167

doi: 10.12795/themata.2015.i51.08 


\section{La cabaña de Todtnauberg}

La humilde cabaña del hombre sabio de Epicteto reaparece en el que para muchos es el más grande filósofo del siglo XX. En septiembre de 1933, Heidegger rechazaba por segunda vez una oferta para ocupar una cátedra de filosofía en la Universidad de Berlín. La justificación de su negativa, un texto fechado en 1934 que luego aparecería en el volumen Aus der Erfahrung des Denkens y titulado significativamente "¿Por qué permanecemos en la provincia?», encerraba todo un alegato a favor de su "mundo de trabajo» (Arbeitswelt) frente al «mundo de la ciudad» (städtische Welt). En este breve y bello escrito, Heidegger no describía su trabajo filosófico en la cabaña de Todtnauberg "cual apartada ocupación de un extravagante», ${ }^{5}$ sino que más bien lo vinculaba íntimamente al mundo de las montañas de la Selva Negra y sus campesinos: «la totalidad de mi trabajo está sostenida y guiada por el mundo de estas montañas y sus campesinos». Esto no sería sino un testimonio autobiográfico más del idilio alemán con la naturaleza si no fuera porque constituye al mismo tiempo un ejemplo de mitología del suelo acentuadamente crítico con la civilización urbana y basado en la dicotomía contrastante campo/ciudad. En efecto, Heidegger reivindicaba para sí mismo una especie de soledad que no creía compatible con el aislamiento de la ciudad. Sólo en esta soledad la existencia del hombre sería arrojada a "la extensa vecindad de la esencia de todas las cosas», mientras que en la ciudad se vería obligado a perder el tiempo de trabajo debido a gestiones, viajes para dictar conferencias, discusiones y otras mundanidades relacionadas con su actividad docente. ¿No serían los hombres de la ciudad los destinatarios, después de todo, de las lecciones de la furiosa tormenta de nieve que el filósofo había escuchado antes batirse en torno a su cabaña? Pero no, Heidegger no extrae esa conclusión. En el lenguaje de Sein und Zeit, no sería difícil asociar la vida del campesino con la existencia auténtica y la del hombre de la ciudad con la inauténtica. El filósofo de Messkirch, un hombre de pueblo, no podía encontrar ningún estímulo para su pensar en la ciudad, pues éste no lo encontraba ni siquiera en el campo, que es a lo más que puede llegar el urbanita en su estadía campesina según él, sino que lo asimilaba a "un centenario arraigo suabo-alemán al suelo». Los surcos que él procuraba para sembrar las semillas de su pensamiento no podrían abrirse nunca en medio del asfalto de la metrópolis berlinesa.

¡De qué forma tan diferente 'estimulaba' la ciudad a Walter Benjamin! El filósofo alemán establece una analogía entre el bosque y la ciudad que desarticula, a mi juicio, la contraposición tradicional campo/ciudad.

[5] “Por qué permanecemos en la provincia?”, en M. Heidegger, De la experiencia del pensar, Universidad de Chile, Santiago, 1983, p. 2 (Gesamtausgabe, vol. 13, Klostermann, Frankfurt, 1983, $\left.2002^{2}\right)$.

THÉMATA. Revista de Filosofía, №51 enero-junio (2015) pp.: 145-167

doi: 10.12795/themata.2015.i51.08 
«Importa poco no saber orientarse en una ciudad -dice-, perderse en cambio, en una ciudad como quien se pierde en el bosque, requiere aprendizaje. Los rótulos de las calles deben entonces hablar al que va errando como el crujir de las ramas secas, y las callejuelas de los barrios céntricos reflejarles las horas del día tan claramente como las hondonadas del monte». ${ }^{6}$

Si Descartes aconsejaba seguir el camino recto para salir del bosque en que nos hemos perdido, Benjamin piensa que hay que saber perderse en la ciudad, errar por su laberinto de calles y plazas como quien no quiere salir del bosque. No merece la pena, pues, pararse a refutar la oposición superficial ciudad/campo que subyace en el provincianismo de nuestro pensador filoagrario. Lo que el hombre hace no es otra cosa que urbanizar la naturaleza llevando siempre que puede la ciudad al campo o el campo a la ciudad. La mecanización de la agricultura o la creación de zonas verdes en las ciudades son un ejemplo de esto último. La exterioridad de la ciudad no es ya la selva o, en su caso, el campo, sino aquello que cae fuera de la antroposfera y que para nosotros es y seguirá siendo una incógnita, lo otro del hombre y su mundo.

A diferencia de Heidegger, con el nombre de filosofía deberíamos entender un conjunto de reflexiones sobre el "hombre" y no sobre las "cosas". La hora propicia para la filosofía está bien lejos del bramido de una furiosa tormenta de nieve sacudiéndose en torno a la cabaña de la Selva Negra. La hora de la filosofía tuvo lugar en la plaza pública, en el mercado del mundo antiguo, y no en el fogón de Heráclito. La filosofía, hoy, a su vez, no puede hacer dejación de su responsabilidad en la tarea de repensar la ciudadanía contemporánea. Pero Heidegger parece ignorar la importancia de la cosa pública y de la ciudad como factores propiciatorios de la experiencia filosófica o, al menos, como temas en sí mismos, no menos que el habitar y el construir, dignos de ser pensados. No por casualidad, una de las críticas más serias que se han hecho a su filosofía, es que ésta desconoce el problema del otro, es decir, que este pensamiento carece de una respuesta satisfactoria a las cuestiones que plantea la vida en común con los otros. Pues bien, ¿no es la ciudad, la plaza pública, el lugar propicio donde se plantea el magno problema filosófico de nuestra convivencia?, ¿puede un filósofo que se precie "echarse al monte" e ignorar, en la lengua viva de Machado, "lo que pasa en la calle"? Mi respuesta es la misma de Heidegger al segundo llamado de Berlín: jirrevocablemente no!

\section{La ciudad como "metáfora absoluta"}

Más radical que la oposición campo/ciudad es la necesidad de neutralizar la impresión dejada por la naturaleza sobre el pequeño mundo del hombre, el deseo de mantenerla a distancia mediante el conjunto de tecnologías que lla-

[6] W. Benjamin, Dirección única, Alfaguara, Madrid, 1987, p. 15.

THÉMATA. Revista de Filosofía, No51 enero-junio (2015) pp.: 145-167 doi: 10.12795/themata.2015.i51.08 
mamos cultura. Según Blumenberg, «al hombre contemporáneo [...] le horroriza permanecer mucho tiempo en la naturaleza, cruzado de brazos; cosa que evidencia tanto el huertecillo como las diversas maneras de acompañar a los presuntamente necesitados de naturaleza con toda una parafernalia de utensilios técnicos, que neutralizan la impresión dejada por ella». ${ }^{7}$ En un capítulo de su impresionante Höhlenausgänge (1989), Blumenberg nos ha presentado, por cierto, la ciudad como una "repetición de la caverna con otros medios», ${ }^{8}$ una especie de prolongación artificial del útero materno donde el hombre consigue mantener a distancia una naturaleza exterior que siempre se le ha mostrado hostil y amenazadora. El impacto brutal de la realidad sobre la conciencia es amortiguado esta vez por el compendio de instancias mediadoras que la ciudad brinda a sus habitantes en toda la gama de su variopinta oferta. Desde este punto de vista, los males de una urbe nos compensarían ampliamente en comparación con el gran mal del que ésta nos pone a salvo: el absolutismo de la realidad. Así, el tan vilipendiado ruido de la capital, por poner sólo un ejemplo, tiene que sonarnos necesariamente a música celestial cuando lo comparamos con el espanto pascaliano ante el «silencio eterno de los espacios infinitos».

Una de esas técnicas de la cultura con la que conseguimos mantener alejada de nosotros la naturaleza es, sin duda, la filosofía. Pero la cultura está ligada íntimamente a la aparición histórica de las ciudades. El homo historicus es un homo urbanus. ¿En qué sentido digo, por tanto, que la filosofía es un fenómeno urbano? En primer lugar, porque sin la existencia de las ciudades históricas, de las urbes, no creo que hubiera sido posible la fundación de academias y, por consiguiente, la aparición de la filosofía como tal. En efecto, «La filosofía no nació en calmo retiro, sino en Mileto, el mercado del mundo antiguo en el que los pueblos del Mediterráneo procedían al cambio de sus mercancías; y los más antiguos pensadores no fueron ascetas alejados del mundo, sino hombres distinguidos, curiosos y abiertos al mundo, políticos en parte». ${ }^{9}$ Ahora bien, la mera constatación empírica de que la filosofía ha nacido en el marco cultural de la ciudad no es suficiente en sí misma para calificar a aquélla como un fenómeno típicamente urbano. Los dioses de Epicuro filosofan plácidamente en los espacios interestelares y el filósofo autodidacto de Ibn Tufail no parece necesitar de la comunidad humana para alcanzar la sabiduría. La pregunta que se

[7] H. Blumenberg, Las realidades en que vivimos, Paidós, Barcelona, 1999, p. 83, n. (la cursiva es mía). De este horror del homo urbanus a la naturaleza nos ha dejado Ortega y Gasset un gráfico testimonio: «en la ciudad, la lluvia es repugnante, porque es una injustificada invasión del cosmos, de la naturaleza primigenia en un recinto como el urbano, hecho precisamente para alejar lo cósmico y primario».

[8] H. Blumenberg, Salidas de caverna, Antonio Machado Libros, Madrid, 2004; cfr. para una ontología del espacio cerrado P. Sloterdijk, Esferas II. Globos, Siruela, Madrid, 2004, especialmente el capítulo III titulado: "Arcas, murallas de ciudad, fronteras del mundo, sistemas de inmunidad", pp. 219 ss.

[9] W. Nestle, Historia del espíritu griego, Ariel, Barcelona, 1975, p. 55.

THÉMATA. Revista de Filosofía, No 51 enero-junio (2015) pp.: 145-167 doi: 10.12795/themata.2015.151.08 
plantea es entonces la siguiente: ¿cuáles son las relaciones que se establecen entre filosofía y ciudad, entre ciudadano y filósofo?, ¿es posible la filosofía en un contexto social que no sea urbano o, cuando menos, comunitario?

Ante todo, la ciudad constituye una "metáfora absoluta"10 que ha inspirado modelos de explicación racional entre los mismos filósofos presocráticos. En realidad, el pensamiento griego no siguió el camino de las estrellas a la vida, como se creyó en un principio, sino que más bien se ha limitado a trasladar sus concepciones sobre la sociedad y su organización al mundo exterior, a la naturaleza. Vico fue el primero en advertirlo al establecer que la filosofía civil, el conocimiento de la historia de las naciones, sirve de modelo a la filosofía natural y no al revés. La cosmología de Anaximandro ha podido ser comparada, por ejemplo, con el sistema jurídico de la polis. «Si uno deja la pólis, se llega al campo libre y, tras algún tiempo a otra pólis. Esto guarda relación con la representación de que, fuera de nuestro cosmos, a mayor o menor distancia, se encuentran otros kosmoí, y siempre de nuevo, otros y otros más, sin fin». ${ }^{11}$ ¿Pero acaso el comienzo del pensamiento moderno no encierra también en su base una metáfora urbanística? La ciencia no se construye con opiniones dudosas e inciertas, ni siquiera probables: he ahí el supuesto de que parte Descartes. La duda nace de la necesidad que siente, pues, Descartes de deshacerse por completo de sus antiguas opiniones y empezar de nuevo el edificio del saber. Una metáfora arquitectónica articula el razonamiento de su primera meditación: la ciencia es un edificio que hay que empezar por sus cimientos, o lo que es lo mismo, desde los fundamentos. Pero si los cimientos admitidos hasta ahora no son seguros, lo que se impone es la demolición del edificio. Al intentar deshacerse de sus opiniones y antiguos prejuicios, Descartes está protagonizando un acto de derribo de la tradición cuya metáfora la encuentra tanto en el edificio de cimientos ruinosos como en el trazado anárquico de las villas medievales. Descartes, el filósofo moderno que buscaba una soledad sin aislamiento en la tolerante Amsterdam, se representó su propio método según el modelo de una ciudad de nueva planta racionalmente edificada. En su Discurso del método dice Descartes:

\footnotetext{
«Esas viejas ciudades que no fueron al principio sino aldeas y que con el transcurso del tiempo se convirtieron en grandes ciudades, están ordinariamente muy mal trazadas si las comparamos con esas plazas regulares que un ingeniero diseña a su gusto en una llanura; y, aunque considerando sus edificios uno por uno, encontrásemos a menudo en ellos más arte que en los de las ciudades nuevas, sin embargo, viendo cómo están dispuestos -aquí uno grande, allá uno pequeño- y cuán tortuosas y desiguales son por esta causa las calles, diríase más bien que es el azar, y no la voluntad de unos hombres provistos de razón, el que los ha dispuesto asím. ${ }^{12}$
}

[10] Utilizo esta expresión en el sentido de H. Blumenberg, Paradigmas para una metaforología, Trotta, Madrid, 2003, passim.

[11] W. Bröcker, Die Geschichte der Philosophie vor Sokrates, Frankfurt, 1965, p. 17; citado en H. Blumenberg, La legitimación de la Edad Moderna, Pre-Textos, Valencia, 2008, p. 155.

[12] Discurso del método, $2^{\mathrm{a}}$ parte (Adam-Tannery VI, 11-12). Para el espiritualismo cartesiano, según Bueno, el interés de la filosofía por la Arquitectura, incluso después de recuperado el mundo

THÉMATA. Revista de Filosofía, Nº51 enero-junio (2015) pp.: 145-167

doi: 10.12795/themata.2015.i51.08 
El filósofo francés deduce de aquí, como es sabido, la dificultad de trabajar sobre lo ya hecho por otros y, por consiguiente, la necesidad de construir la ciencia como si pudiese ser realizada exclusivamente por uno mismo.

\section{El filósofo y su ciudad}

En lo que se refiere al filósofo, éste, como tipo humano, resulta impensable sin su ciudad. ${ }^{13} \mathrm{Y}$ es que no hay lugar ameno para él fuera de las murallas de aquélla. Sócrates fue el primero en sentirlo así cuando no pudiendo preguntar a los árboles, como nos refiere la famosa anécdota del Fedro, decide volver a Atenas para poder hablar con sus conciudadanos. «Los árboles y el sitio nada me enseñan, sino los hombres en la ciudad», dice el hijo de Sofronisco. No por otra razón pudo Cicerón hacer de Sócrates el primer filósofo: éste habría bajado del cielo a la filosofía consiguiendo introducirla en las ciudades y en las casas de los hombres. Y si bien la condena de Sócrates provocó el divorcio occidental entre ciudad y filosofía, su muerte es un paradigma, en realidad, del enraizamiento del filósofo ateniense en la polis que le vio nacer, así como de su fidelidad a las leyes de la misma. ${ }^{14}$ Los filósofos griegos, en definitiva, tienden «a vivir en ciudades, bajo tejado, o al lado de pórticos o plazas públicas, es decir, en la proximidad de obras arquitectónicas»: la Escuela de Mileto, la Casa de Calias, la Academia, el Liceo.$^{15}$ Los romanos eran esencialmente urbanos y el cristianismo fue, hasta el final del Imperio, un fenómeno eminentemente urbano. Y si bien en la Edad Media se produce un eclipse de la vida urbana, el pensamiento logra sobrevivir al amparo de monasterios, escuelas y universidades, radicándose estas últimas en ciudades como París y Oxford. Los filósofos modernos viven todos en ciudades: Descartes, Leibniz, Kant, Hegel. Incluso cuando el humanismo parece inclinarse hacia la soledad sólo lo hace pensando en su utilidad para la vida en compañía, como en Fernán Pérez de Oliva. Fuera de la ciudad, no hay lugar para la filosofía.

La lengua latina distingue entre urbs, como urbe, y civitas, en el sentido de ciudad o ciudadanía. Según Arias Montano, «la urbs está formada por murallas y edificios; en cambio, la civitas propiamente dicha está for-

corpóreo a través del Alma y de Dios, tendría siempre un carácter subsidiario; cfr. G. Bueno, "Arquitectura y Filosofía”, en P. Peñalver, F. Giménez, E. Ujaldón (eds.), Filosofía y cuerpo: debates en torno al pensamiento de Gustavo Bueno, Ediciones Libertarias, Madrid, 2005, pp. 422-423.

[13] Véase E. Paci, Il filosofo e la città: Platone, Whitehead, Husserl, Marx, a cura di S. Veca, Il Saggiatore, Milano, 1979.

[14] Para la tradicional enemistad entre ciudad y filosofía cfr., por ejemplo, H. Arendt, La condición humana, Paidós, Barcelona, 1998. Sobre Platón y el sueño roto de su República V. Gómez Pin, El drama de la ciudad ideal. El nacimiento de Hegel en Platón, Taurus, Madrid, 1974. Sobre la vuelta de Sócrates a la ley de la ciudad como norma ética, A. Tovar, Vida de Sócrates, Alianza, Madrid, 1984.

[15] G. Bueno, op. cit., p. 418.

THÉMATA. Revista de Filosofía, Nº51 enero-junio (2015) pp.: 145-167 doi: 10.12795/themata.2015.i51.08 
mada por ciudadanos»; una distinción que matiza posteriormente Fustel de Coulanges: "Ciudad y urbe (cité y ville en francés) no eran palabras sinónimas entre los antiguos. La ciudad era la asociación religiosa y política de las familias y de las tribus; la urbe era el lugar de reunión, el domicilio y, sobre todo, el santuario de esta asociación». ${ }^{16}$ La filosofía se ha ocupado, ciertamente, de la civitas, pero no lo ha hecho de la urbs; no ha reflexionado lo suficiente sobre el condicionamiento que ejercen los distintos tipos de urbes sobre las formas de organización social y el concepto mismo de ciudadanía. Una clasificación de los tipos de ciudades podría arrojar alguna luz sobre las distintas formas que ha tenido la filosofía de entender la relación entre el hombre y el ser ciudadano a lo largo de su historia. Pues no es la misma ciudad la Atenas de Pericles que la Nápoles de Vico o la Viena de Wittgenstein. La primera es una ciudad-estado que mantiene un equilibrio dinámico entre el estatismo extremo representado por el dorismo y el individualismo jónico; la segunda, la capital de un reino "gobernato in provincia", cada vez más alejada del circuito de la gran política europea; y la última, un centro de enorme actividad científica, intelectual y artística a pesar de (o precisamente por) haber perdido su hegemonía política como capital del imperio austrohúngaro. Tres marcos culturales en cualquier caso muy diferentes que determinan necesariamente la relación entre el individuo y la comunidad política en la Antigüedad y en los tiempos modernos.

Podemos distinguir tres tipos básicos de ciudades según el modo de producción en el que se hayan basado: la esclavista de la Antigüedad, la feudal de la Edad Media y la capitalista o industrial de la Edad Moderna. ${ }^{17}$ La polis griega se opone a las ciudades-imperios de Egipto, Asiria, Babilonia o Persia, organizadas todas ellas según un modelo teocrático de monarquías centralizadas y autoritarias. En contraste con este modelo, la democracia de Atenas se hace efectiva y directa en el siglo V a. C. por obra de Pericles. Aunque los ciudadanos libres forman menos de la cuarta parte de la población, son todos iguales en el derecho a hablar (isegoría). No es nada extraño que la filosofía se haya vuelto en esta época, de mano de Sócrates y los sofistas, hacia las cuestiones que giran directamente en torno al hombre, tales como la educación para vivir en democracia o la organización política. Los sofistas no son maestros de verdad, como lo fueron Anaximandro, Parménides o Heráclito, sino maestros de areté política, los profesores de la democracia del mundo griego que enseñaban todo aquello que el hombre necesita para desarrollar una vida activa en la polis. Al contrario de la ciudad-estado antigua de la cultura clásica, la actividad de los burgos laicos y

[16] Arias Montano, Libro de José o sobre el lenguaje arcano, Universidad de Huelva, Huelva, 2006, p. 322; Fustel de Coulanges, La ciudad antigua, Porrúa, México, 1998, p. 96.

[17] Para la ciudad en la historia, véase la anhelada reedición del clásico de L. Mumford, La ciudad en la historia: sus orígenes, transformaciones y perspectivas, Pepitas de Calabaza, Logroño, 2012.

THÉMATA. Revista de Filosofía, No51 enero-junio (2015) pp.: 145-167

doi: 10.12795/themata.2015.i51.08 
de las ciudades episcopales de la Edad Media fue prácticamente nula desde el punto de vista municipal y económico. Según algunos historiadores, «en el conjunto de Europa, la población urbana, desde el siglo XII hasta el XV, nunca fue muy superior a la décima parte del total de los habitantes». ${ }^{18} \mathrm{En}$ esta sociedad predominantemente agrícola no existen los ciudadanos, sino siervos y propietarios de la tierra. No obstante, puede hablarse también de un renacimiento de la vida urbana en la Edad Media como consecuencia de las aglomeraciones mercantiles que se asientan en el interior, primero, y en las afueras de las villas, más tarde. La ciudad moderna tuvo, pues, su origen en el arrabal de la villa medieval y está indisolublemente ligada al resurgimiento de la vida comercial tras un período en el que se había prácticamente extinguido de Occidente. Así pues, si en la ciudad antigua sólo unos pocos son ciudadanos y en la feudal del Medioevo no hay lugar para ciudadanía alguna, en la ciudad industrial de la Edad Moderna son los burgueses fundamentalmente quienes reclaman para sí el derecho de ser llamados ciudadanos. Pero con el paso del tiempo esta condición habría de hacerse extensiva a todos los seres humanos. La esclavitud y la servidumbre características de la ciudad antigua y de la villa medieval son incompatibles con nuestro concepto ilustrado y democrático de ciudadanía. En la ciudad industrial moderna rige, por el contrario, el principio de cada cual para sí mismo que Balzac describió como «el evangelio de todas las capitales» en una novela como César Birotteau, aparecida en 1837, donde se narra la historia de un comerciante perfumista que había dejado su Turena natal para hacer fortuna en París. La ruda aplicación de este principio individualista hace que César encuentre la vida en la ciudad sumamente dura en contraste con la Turena «donde el albañil coloca la piedra en doce tiempos, donde la pereza se mezcla sabiamente con el trabajo. Pero se dormía sin tiempo de pensar en huir, porque a la mañana siguiente tenía que hacer nuevos recados, y cumplía su deber con el instinto de un perro guardián». ${ }^{19}$ La ciudad mecanizada surgida de la revolución industrial se basa en el desarrollo de la industria y el comercio, pero ahora el burgués, en contraposición al esclavo y al siervo de la Antigüedad y de la Edad Media, es libre para reafirmar frente a la sociedad su autonomía como individuo a través de la fuerza misma de su trabajo.

La diferencia entre los distintos sistemas filosóficos acaso pueda ilustrarse por la urbanística y la arquitectura. La ciudad antigua está construida según el plano racional ideado en el siglo $\mathrm{V}$ a. C. por un arquitecto, Hipódamo de Mileto, considerado tradicionalmente como el padre del urba-

[18] H. Pirenne, Historia económica y social de la Edad Media, FCE, México, 1976, p. 49; para las ciudades de la Edad Media cfr. del mismo autor, Las ciudades de la Edad Media, Alianza, Madrid, 1972.

[19] Balzac, César Birotteau, Planeta, Barcelona, 1982, p. 26.

THÉMATA. Revista de Filosofía, Nº51 enero-junio (2015) pp.: 145-167

doi: 10.12795/themata.2015.i51.08 
nismo. Este planeamiento urbano, apoyado en calles anchas que se cruzaban en ángulos rectos, formaba una red viaria dominada por la simetría. La exigencia de dar razón de todas las cosas que caracteriza a la filosofía griega parece tener un correlato urbanístico en el trazado hipodámico. La ciudad, no menos que el mundo, participa del lógos constituyendo un sistema organizado, un espacio político perfectamente integrado en el orden natural. La palabra cosmos designa tanto la estructura del universo como el funcionamiento de la sociedad humana política. Ahora bien, frente al trazado natural de las antiguas aldeas, sólo un trazado planificado como el de Hipódamo podía hacer de la ciudad antigua un cosmos humano. El individuo forma parte de la ciudad y ésta de la naturaleza en un conjunto sin solución de continuidad. La escala reducida de la ciudad creaba un tipo de ciudadano para el que el deber de ayudar a su comunidad era una cuestión de sentido común: un individuo universal y polifacético (L. Racionero). En el mundo antiguo, los conceptos de hombre y ciudadano son naturalmente equivalentes.

$\mathrm{Al}$ igual que la antigua, la sociedad medieval se basa en un modelo organicista: la sociedad está por encima del individuo. Pero a diferencia de la antigua, la ciudad medieval carece por completo de vida municipal. Como el siervo al señor feudal, la filosofía queda subordinada a la teología (philosophia ancilla theologiae) y pierde su vinculación con la ciudad. En la Edad Media el campo domina a la ciudad. El papel de ésta como foco de cultura en el mundo antiguo es asumido ahora por la Iglesia y sus monasterios que se encargan de conservar, recuperar y transmitir la cultura y el saber clásicos. Por si fuera poco, el cristiano, desde San Agustín, no tiene otra patria que la invisible Ciudad de Dios, simbolizada por Jerusalén y opuesta, a pesar de estar mezcladas, a esa otra ciudad terrena o ciudad del diablo que es siempre para él la ciudad de los hombres. Hombre y ciudadano, sociedad y ciudad se disocian. No me resisto a citar a este respecto las palabras de un pensador tradicionalista español:

«Para el mundo pagano la sociedad y la ciudad eran una cosa misma. Para el romano la sociedad era Roma; para el ateniense, Atenas. [...] El cristianismo reveló al hombre la sociedad humana; y como si esto no fuera bastante, le reveló otra sociedad mucho más grande y excelente, a quien no puso en su inmensidad ni términos ni remates. De ella son ciudadanos los santos que triunfan en el cielo, los justos que padecen en el purgatorio y los cristianos que combaten en la tierra». ${ }^{20}$

Si es difícil, pues, que en estas circunstancias el medio urbano pueda desempeñar algún papel en la autoconciencia del hombre en la Edad Media, ello no ha sido un obstáculo para la aparición de metáforas ar-

[20] Donoso Cortés, Ensayo sobre el catolicismo, el liberalismo y el socialismo, Editora Nacional, Madrid, 1978, p. 121. Cfr. E. Gilson, Las metamorfosis de la Ciudad de Dios, Rialp, Madrid, 1965.

THÉMATA. Revista de Filosofía, No51 enero-junio (2015) pp.: 145-167 doi: 10.12795/themata.2015.i51.08 
quitectónicas en relación a la filosofía aristotélico-escolástica. Para Santo Tomás, la verdad de los seres naturales en el entendimiento divino podía compararse con la de los productos artificiales por el orden que dicen al entendimiento humano del que dependen; "y así hablamos de un edificio verdadero cuando reproduce la forma que hay en la mente de su arquitecto». ${ }^{21}$ Galileo utilizó la metáfora de la fábrica para referirse polémicamente al paradigma científico de Aristóteles representado por la figura de Simplicio en su Dialogo sopra i due massimi sistemi del mondo. En lo que se refiere a las grandes summas de los escolásticos medievales, éstas han podido ser comparadas con las catedrales de su época. Pero si la filosofía moderna, representada paradigmáticamente por Descartes, apelaba a un modelo de urbanismo racional para ilustrar las pretensiones teóricas del nuevo método, era porque rechazaba en el fondo la filosofía escolástica, cuya naturaleza compuesta se comparaba explícitamente con la de los edificios y ciudades del Medioevo. El método artificialmente complicado de la escolástica tardía, con sus cuestiones disputadas y elenco de autoridades, la elefantiasis, en una palabra, de los sistemas escolásticos, parece corresponderse aquí con el plano irregular, las calles estrechas y tortuosas de las ciudades medievales, tanto musulmanas como cristianas. De hecho, en la época de Descartes, como apunta Blumenberg, las ciudades planificadas llevarán el nombre de villes à la Descartes, estableciéndose así una intersección entre urbanística y filosofía en el comienzo de la Modernidad. Ahora bien, a diferencia de los filósofos medievales, ocupados en los arcos de bóveda, las torres y las agujas de sus sistemas, Descartes se habría ocupado de la solidez de los cimientos del edificio del conocimiento. «En cuanto a las demás ciencias, como toman sus principios de la filosofía, juzgaba yo que no se podía haber edificado nada sólido sobre cimientos tan poco firmes». ${ }^{22}$ La obsesión moderna por la fundamentación-cimentación llega hasta Kant, el cual se ha servido asimismo de una metáfora arquitectónica para indicar el uso acrítico de la razón: ahora no se trata de derribar, como en Descartes, el edificio del saber para construir la ciencia según el modelo de un urbanismo racional y básicamente escéptico respecto al valor epistemológico del testimonio de nuestros sentidos, sino, justo al contrario, de hacer ver la "aparente solidez» de esos presuntos conocimientos que tratan de extenderse más allá del «campo de toda experiencia posible». ¿No era, en efecto, el cogito, un paradigma del uso acrítico de la razón realizado por la psicología racional? No obstante, la precipitación y

[21] S. Th., I, q. 16, a. 1.

[22] Discurso, $1^{a}$ parte (VI, 8-9); cfr. H. Blumenberg, La inquietud que atraviesa el río, Península, Barcelona, 2001, p. 82: «La insistencia en la verificación del terreno y del suelo, en la capacidad de soportar los cimientos y levantar sobre ellos, caracteriza el carácter de «profundidad» teórica de la época moderna».

THÉMATA. Revista de Filosofía, Nº51 enero-junio (2015) pp.: 145-167

doi: 10.12795/themata.2015.i51.08 
la falta de una cimentación adecuada, antes que un trazado urbanístico defectuoso, serían aún las responsables de la debilidad del edificio de la razón: "Pero suele ocurrirle a la razón humana que termina cuanto antes su edificio en la especulación y no examina hasta después si los cimientos tienen el asentamiento adecuado». ${ }^{23}$ Si Kant, pues, erigió un tribunal de la razón era tanto para atemperar los altos vuelos de la metafísica, que todavía Vico personificaba con las sienes aladas en el grabado del frontispicio de su Scienza Nuova, como para vigilar que la cimentación-fundamentación del edificio del conocimiento se examine antes (a priori) y no después de la propia construcción del mismo.

\section{Sobre el origen de la ciudad}

Pero en el principio no fue la ciudad. Según Vico, antes de asentarse en ciudades, la humanidad tuvo que pasar por las selvas, las chozas y los poblados. ${ }^{24}$ La filosofía nace, pues, después de la fundación de la ciudad, o sea, cuando las academias están en condiciones de respaldarla institucionalmente. En un pasaje verdaderamente capital de la Scienza Nuova, Vico ha mostrado cómo la filosofía surge y va unida a la vida social y política. Así, en relación a Sócrates, dice el filósofo napolitano que éste había esbozado los géneros inteligibles «viendo cómo los ciudadanos atenienses al dictar las leyes acababan poniéndose de acuerdo en una misma idea de igualdad»; y Platón, por su parte, se habría elevado a meditar sobre las ideas inteligibles a partir de la reflexión de que en las asambleas públicas las mentes de los hombres particulares se unen a una idea desapasionada del bien común; finalmente, Aristóteles, entendiendo que la justicia se asienta en el ánimo del héroe y gobierna sobre todas las demás virtudes, «había observado que la justicia legal mandaba sobre la prudencia del senado, sobre la fuerza en los ejércitos, sobre la templanza en las fiestas, sobre la justicia particular, tan distributiva en los erarios como conmutativa en el foro». La conclusión de Vico no puede ser más instructiva para el argumento de este ensayo: «De todo ello se concluye que tales principios de metafísica, de lógica, de moral surgieron en la plaza de Atenas». ${ }^{25}$ Dicho de otra manera: que si no hubiera habido repúblicas, o sea, ciudades, "no habría habido absolutamente filósofos en el mundo».

¿Cuál es, pues, el origen de la ciudad? La Biblia y el mito de Rómulo y Remo están de acuerdo a la hora de asignar al asesinato del hermano

[23] $K r V$, A 5/ B 9.

[24] Cfr. SN 44, § 239: «El orden de las cosas humanas fue éste: primero existieron las selvas, después las chozas, de aquí se pasó a los poblados, luego las ciudades y, finalmente, las academias».

[25] SN 44, §§ 1040-1043. (Agradezco al profesor Antonio Romero Ysern haber llamado mi atención sobre este pasaje).

THÉMATA. Revista de Filosofía, Nº51 enero-junio (2015) pp.: 145-167 doi: 10.12795/themata.2015.i51.08 
el comienzo de la prehistoria de la ciudad. Tras matar a su hermano Abel, Caín edifica una ciudad para esconderse de la presencia de Yahvé, pero probablemente también para evitar ser asesinado. Invisibilidad y seguridad serán a partir de entonces dos rasgos comunes a toda ciudad. La vulnerabilidad del hombre en el estado de naturaleza se consigue contrarrestar mediante la creación de un medio artificial dentro del cual no sólo gozamos de las ventajas de la asociación con nuestros congéneres, sino también hacernos invisibles para ellos. El anonimato del hombre de la multitud en nuestras actuales megalópolis es el precio a pagar por quienes no quieren dejar de beneficiarse de la discreta invisibilidad que otorga el conglomerado urbano. A diferencia del relato bíblico, que parece ver en el paso del nomadismo al sedentarismo la raíz de todo mal, el rito de la fundación de Roma reproduce el sacrificio cosmogónico primordial común a tantas otras tradiciones. Pues si bien es cierto que la ciudad supone una especie de ruptura del hombre con el orden natural, no lo es menos que ella tiene la virtualidad de representar simbólicamente al mundo. El símbolo sagrado de Roma, situado sobre el Palatino, no era otro que el Mundus, un hoyo donde los primeros habitantes habían depositado objetos de necesidad doméstica y un terrón del campo patrimonial y al que dieron, según Plutarco, el mismo nombre que el cielo. ${ }^{26}$ Así y todo, ambos relatos coinciden en señalar el carácter contra natura de la ciudad. Ésta nace de un fratricidio original, o presupone una víctima sacrificial; en cualquier caso, nos habla de un proceso histórico de segregación por el que el individuo acaba primando las relaciones de vecindad sobre los intereses de la familia o de la tribu. El abandono de nuestra tribu, de la fratria, es la condición sine qua non para la aparición de esos focos de civilidad que son las ciudades.

El efecto civilizador de las ciudades, por lo demás, ha sido descrito magistralmente por Luis Racionero en un ensayo de culto, El Mediterráneo y los bárbaros del Norte:

«La diversidad y la mezcla son la esencia de la vida urbana, la ciudad es un instrumento generador de innovaciones; más que las universidades, bibliotecas, laboratorios y ateneos, es la ciudad el artificio civilizador por excelencia: en el intercambio de paseo y ágora, plaza y mercado, calle y pórtico, la gente se encuentra, charla, comercia, aprende, copia, observa, se informa, por el mero hecho de salir a la calle; en esto reside la esencia de la urbanidad». ${ }^{27}$

No obstante, para que haya ciudad se requiere algo más que la mera

[26] Sobre el mito de la fundación de Roma, cfr. Tito Livio, I, 3 y sigs.; Ovidio, Fasti II, 381 y sigs.; Dionisio de Halicarnaso, Antiquit. Rom. I, 76 y sigs.; Plutarco, Romulus III, XI; etc.

[27] L. Racionero, El Mediterráneo y los bárbaros del Norte, Plaza \& Janés, Barcelona, 1996, p. 46 (con bibliografía especializada en las págs. 63-64).

THÉMATA. Revista de Filosofía, Nº51 enero-junio (2015) pp.: 145-167

doi: 10.12795/themata.2015.i51.08 
libertad negativa de romper los lazos que nos unen con nuestro clan familiar. Ni siquiera nos basta con un recinto para poder edificar la ciudad. Sin política, las puertas y murallas de la urbs, a fuer de necesarias, no son suficientes para que haya civitas. Sin asociación política (ayuntamiento) no hay ciudad. La exhortación que Tucídides pone en boca del estratego Nicias es bien clara a este respecto: "Una ciudad son sus hombres y no unos muros ni unas naves sin hombres». ${ }^{28}$ Nicias parece dar la razón por anticipado a Fustel de Coulanges acerca de la prioridad de la civitas sobre la urbs cuando en el mismo pasaje dice delante de sus soldados: pensad, por el contrario, que vosotros constituís de inmediato una ciudad dondequiera que os asentéis... ¿Dondequiera? La enorme variedad de hábitats donde históricamente se han edificado ciudades confirmaría este dictamen.

El mito de Prometeo, puesto en boca de Protágoras por Platón, demuestra la imposibilidad de la ciudad sin el desarrollo de lo que hoy se llaman virtudes cívicas. Que lo que mantiene a los hombres unidos, en última instancia, dependa de un dios, y no de Prometeo, es la manera que tiene el mito de relativizar el robo del fuego por parte del titán, mostrándonos que los dioses tienen la última palabra sobre el destino del hombre. Esta es una posible explicación. Lo que les faltaba a los hombres era el respeto y el sentido de la justicia. El valor de estas virtudes consiste en que sin ellas no es posible la convivencia pacífica entre los hombres y, por tanto, tampoco la fundación de ciudades. Así, pues, la supervivencia posibilitada por el saber técnico era en sí misma precaria si al hombre no le era dado contar aún con el arte político. En poder de Zeus, el sentido moral (aidōs) y la justicia (díkē) no era algo que Prometeo hubiera podido robar tranquilamente para ofrecérselo como galardón a los hombres. Así, mientras las diferentes técnicas manuales fueron repartidas desigualmente, el sentido moral y la justicia, condición para que haya «orden en las ciudades y ligaduras acordes de amistad», ${ }^{29}$ tenían que ser infundidas a todos los hombres por igual. El significado de esta diferencia reside en que, si bien el reparto desigual de las técnicas es necesario para que en la ciudad haya diversas especialidades, el reparto de la técnica política ha de ser el mismo para todos, pues tanto el respeto como la justicia son virtudes que han de ser comunes para lograr la convivencia entre todos los ciudadanos: «Pues no habría ciudades, si sólo algunos de ellos participaran, como de los otros conocimientos»; ${ }^{30}$ aún así, al no poder garantizar la universalidad de la participación en las virtudes morales, Zeus tiene que imponer la ley de que se eliminen como a una enfermedad de la ciudad a todos los incapaces de participar en las mismas.

[28] Tucídides, VII, 76-77 (trad. de A. Guzmán Guerra).

[29] Platón, Protágoras, 322 c.

[30] Prot., 322 d.

THÉMATA. Revista de Filosofía, Nº51 enero-junio (2015) pp.: 145-167 doi: 10.12795/themata.2015.i51.08 


\section{La ciudad como problema filosófico}

Carecemos de una teoría filosófica de la ciudad ${ }^{31}$ ¿Qué es una ciudad? Para Toynbee, «Una ciudad es una agrupación humana cuyos habitantes no pueden producir, dentro de sus límites, todo el alimento que necesitan para subsistir» ${ }^{32}$ La revolución urbana consistió en el paso de la aldea neolítica, de carácter exclusivamente agrario, a una comunidad de artesanos, gobernantes, funcionarios y mercaderes que viven del excedente producido por los agricultores-ganaderos, los cuales habitaban ciertamente en aldeas fuera de los muros de la ciudad, pero también dentro de la misma. El signo utilizado por los egipcios para referirse a la ciudad aludía al cruce de caminos dentro de un recinto amurallado que parece caracterizar a este tipo de asentamientos humanos. Lo que hace una ciudad, pues, es el intercambio de productos dentro de un recinto relativamente seguro: el excedente de producción y, como consecuencia de éste, la especialización de funciones son condiciones suficientes y necesarias para la creación de la ciudad. «La riqueza por sí sola no genera una ciudad, aunque sea un requisito necesario; lo que hace surgir una ciudad es la complejidad debida a la especialización y la diversificación: la ciudad es el corolario espacial de la especialización funcional», ${ }^{33}$ Aristóteles nos ha dado la definición de la polis clásica, entre cuyos rasgos, se encuentra, claro está, el económico: «La ciudad es la comunidad, procedente de varias aldeas, perfecta, ya que posee, para decirlo de una vez, la conclusión de la autosuficiencia total, y que tiene su origen en la

[31] Entre los "grandes" pensadores habría que citar, en primer lugar, a Platón, al Bacon de la Nueva Atlántida y a Marx, sin olvidarnos de las teorías teológicas y utópicas de San Agustín (De civitate Dei, 413/26) y Campanella (Ciudad del Sol, 1623). En el siglo XX, unos, como O. Spengler, La decadencia de Occidente, vol. II, cap. 2: "Ciudades y pueblos", Espasa Libros, Madrid, 1998 y A. Toynbee, Ciudades en marcha, Alianza, Madrid, 1984, han centrado su atención, respectivamente, en "el alma de la ciudad" y en la explosión urbana a la luz de la historia de las ciudades; otros, como G. Simmel, "La metrópolis y la vida mental", en M. Bassols, R. Donoso et al. (coomps.), Antología de sociología urbana, UNAM, México, 1988, pp. 47-61 y W. Benjamin, Iluminaciones II, Taurus, Madrid, 1972; íd., Libro de los Pasajes, Akal, Madrid, 2005, han destacado, por un lado, la influencia de la gran ciudad en la vida psíquica del "hombre metropolitano", y por otro, los aspectos inquietantes y amenazadores de la París de Baudelaire, así como su lugar estratégico en el conflicto entre las clases; M. Weber, Economía y sociedad, FCE, México, 1964, vol. II. p. 938 ss.; íd., La ciudad occidental y la oriental, en Antología de sociología urbana cit., pp. 63-75 se había ocupado ya de analizar la tipología de las ciudades, mientras que los principios de la sociología marxista fueron aplicados al urbanismo por H. Lefevbre, El derecho a la ciudad, Península, Barcelona, 1978; íd., De lo rural a lo urbano, Península, Barcelona, 1978, en tanto que los filósofos españoles E. Trías, El artista y la ciudad, Anagrama, Barcelona, 1976 y G. Bueno, "Teoría general de la ciudad" en Abaco 6 (Primavera 1989), pp. 37-48, han abordado el tema de la ciudad desde la estética y el materialismo filosófico. Sobre la ciudad en las artes y en la literatura, cfr., por ejemplo, el magnífico número monográfico de Litoral. Revista de la Poesía, el Arte y el Pensamiento, 244, 2007.

[32] A. Toynbee, op. cit., p. 16.

[33] L. Racionero, op. cit., p. 49.

THÉMATA. Revista de Filosofía, Nº51 enero-junio (2015) pp.: 145-167

doi: 10.12795/themata.2015.i51.08 
urgencia del vivir, pero subsiste para el vivir bien». ${ }^{34}$ En efecto, la organización de los diversos oficios tendía a realizar el que era, para los pensadores griegos, la gran finalidad de la polis, ser autárquica, pero lo cierto es que cuando una ciudad no lograba bastarse a sí misma tenía que acudir necesariamente al comercio. Así, pues, la autosuficiencia de la ciudad nunca es total, si bien sigue siendo verdad que, aun teniendo su origen en la urgencia de sobrevivir, la ciudad subsiste principalmente, como dice Aristóteles, con vistas a la vida buena. La ciudad no nace para dialogar en la plaza, como pensaba Ortega y Gasset, sino por la simple necesidad que tienen los hombres unos de otros, en primera instancia, para sobrevivir, y en segunda, para vivir bien.

La famosa definición aristotélica del hombre como animal político no hay que entenderla, sin embargo, como si la dimensión política fuera una nota universal de la condición humana, sino simplemente como la autoproclamación del hombre griego en tanto un ser llamado a vivir en el marco institucional de una ciudad-estado. Ser ciudadano significa aquí participar de un culto y de unas tareas comunes frente a los que no participan de esta forma de vida, como los esclavos y los extranjeros residentes (metecos) o los bárbaros. Este carácter aristocrático de la polis determina que la democracia de las ciudades griegas sea cuando menos una democracia especial, pues no todos los que en ella viven son ciudadanos. Pero desde la Declaración de los Derechos del Hombre y del Ciudadano de 1789 aquella restricción aristocrática que afectaba a la ciudad antigua ya no resulta admisible. Como ciudadanos, hoy, todos tenemos formalmente los mismos derechos y los mismos deberes, sin importar estatus, rol o condición alguna. Identificados en el mundo antiguo, hombre y ciudadano son separados por el cristianismo en virtud de la visión agustiniana de la historia como lucha entre las dos ciudades. Pues bien, si en la ciudad nacional moderna el hombre ha redescubierto su condición de ciudadano, en la postmoderna ciudad cosmopolita de nuestros días ya no será posible una identificación entre hombre y ciudadano como la que vimos en la ciudad antigua. Ya no existen las dos ciudades, sino una sola ciudad terrenal donde todos gozamos presuntamente del derecho de participar de una misma ciudadanía universal. Nuestra condición universal de ciudadanos tiene hoy al menos tres dimensiones: local, nacional y mundial. Pues somos ciudadanos de nuestra localidad, de nuestro país, pero también, aunque nos cueste creerlo, somos ciudadanos del mundo por el sólo hecho de pertenecer a la especie humana y de habitar el mismo planeta.

Por eso, porque la ciudad mundial es hoy nuestra patria, pensar el cosmopolitismo se ha vuelto una tarea prácticamente insoslayable para la filosofía contemporánea al menos desde que la aldea global de McLuhan ${ }^{35}$ es una rea-

[34] Aristóteles, Política, 1252b (trad. de C. García Gual y A. Pérez Jiménez); sobre la organización y origen de la polis cfr. un clásico de G. Glotz, La cité grecque, La Renaissance du livre, París, 1928. [35] M. McLuhan, B. R. Powers, La aldea global, Gedisa, Barcelona, 1993. 
lidad del mundo en que vivimos. La humanidad futura será cosmopolita o no será. En efecto, la era de la globalización tiene como presupuesto el paso de la polis a la cosmópolis o a la Ecumenópolis, que diría Toynbee. "Cosmopolitismo" es el nombre con que se conoce a una corriente dentro de la filosofía política y de la filosofía del derecho surgida para responder a los principales desafíos de las democracias en un mundo cada vez más globalizado. ${ }^{36}$ Sin duda, la época helenística había conocido un fenómeno similar cuando hacia el año 200, Alejandría, borrando la significación política de la polis clásica, era ya la mayor ciudad del mundo, ni siquiera sobrepasada por la imperial Roma. No es casualidad que haya surgido también en esta época universalista, como la nuestra, la idea del cosmopolitismo, concretamente en el seno del estoicismo, cuya doctrina de la oikeiosis afirmaba nada menos que la radical unidad del género humano contra la tradición que consideraba a los bárbaros inferiores al griego.

\section{Conclusión}

La filosofía académica de nuestro tiempo presupone la existencia de la ciudad. Sin ciudades no hay academias y, por consiguiente, filosofía. Pero los filósofos, como señalaba Spengler, no han sabido reconocer cuán extraña cosa es la ciudad, razón por la que ha escapado a su percepción el carácter urbano de la actividad filosófica. Y es que con la ciudad pasa lo mismo que con el mundo de la vida: su obviedad ha naturalizado hasta tal punto el fenómeno urbano que el efecto civilizador de aquélla nos ha pasado desapercibido. De ahí que no pueda por menos que resultarnos curiosa, con Wittgenstein, la imagen de unos hombres que para estar más cerca del origen tengan que renunciar paradójicamente a las condiciones de su propia posibilidad y realidad. En este ensayo no me he ocupado, sin embargo, de la ciudad desde el punto de vista de la civitas, sino de la urbs, es decir, del "lugar de reunión" como espacio físico que alberga ese otro espacio antropológico (Bueno) donde los seres humanos afrontamos el difícil reto de hacer posible nuestra convivencia. Pero las murallas y edificios de las viejas ciudades han dado paso en nuestro tiempo a toda una sofisticada red de comunicaciones que ha acabado por definir, frente a la naturaleza y la ciudad, un nuevo espacio social que Javier Echeverría ha caracterizado certeramente como tercer entorno: una ciudad global y a distancia, Telépolis, que posibilita nuevas formas sociales de interacción. ${ }^{37}$ Entre las actividades sociales que Telépolis modifica (la política, la guerra, el derecho, la banca, etc.) hay

[36] Cfr. el volumen colectivo D. Mª . Granja Castro, G. Leyva Martínez (eds.), Cosmopolitismo. Democracia en la era de la globalización, Anthropos, Barcelona, 2009, y mi recensión en Argumentos de razón técnica, 15 (2012), pp. 185-192.

[37] Cfr. J. Echeverría, Telépolis, Destino, Barcelona, 1994; íd., Cosmopolitas domésticos, Anagrama, Barcelona, 1995; íd., Los señores del aire: Telépolis y el tercer entorno, Destino, Barcelona, 1999.

THÉMATA. Revista de Filosofía, No 51 enero-junio (2015) pp.: 145-167

doi: 10.12795/themata.2015.i51.08 
que incluir, sin duda, a la filosofía en cuanto actividad que se desarrolla, no menos que las anteriores, en un marco esencialmente comunitario.

Para meditar el fenómeno de la ciudad, sin embargo, no podemos situarnos ya fuera de sus muros y tratar de sustraernos al poder de seducción de lo urbano; antes bien, tenemos que seguir el consejo de Benjamin y perdernos en ella como quien se pierde en un bosque. Pero no para realizar una filosofía de la ciudad, sino para devolver a las filosofías al lugar que históricamente les corresponde. La filosofía siempre ha querido en vano situarse fuera de contexto para dictarnos $s u$ verdad sobre las cosas. Con ello nos ha ocultado la verdad sobre los hombres. Y así, todavía un Sloterdijk, pretende que los habitantes de la ciudad «no pueden entender suficientemente las condiciones de su propia posibilidad y realidad». Pues se supone que para hacérselas entender está precisamente el filósofo. Esta presunción nos resulta hoy tanto más ridícula por cuanto el filósofo es también un habitante de la ciudad, quizá el urbanita por excelencia, y no puede dejar de querer ser, si es que no quiere salirse al mismo tiempo fuera de los límites de la civilización, sino habitante de ciudad. 


\section{Referencias bibliográficas:}

Aquino, Tomás de: Summa Theologica, 5 vols., BAC, Madrid, 1951-52.

Arendt, Hannah: La condición humana, trad. de Ramón Gil Novales, Paidós, Barcelona, 1998.

Arias Montano, Benito: Libro de José o Sobre el lenguaje arcano, trad. de Baldomero Macías Rosendo y Fernando Navarro Antolín, Universidad de Huelva, Huelva, 2006.

Aristóteles: Política, trad. de Carlos García Gual y Aurelio Pérez Jiménez, Alianza, Madrid, 1995.

Balzac, Honoré de: César Birotteau, trad. de Luis Romero y Carlos Pujol, Planeta, Barcelona, 1982.

Benjamin, Walter: Dirección única, trad. de Juan J. del Solar y Mercedes Allendesalazar, Alfaguara, Madrid, 1987.

Iluminaciones II, trad. de Jesús Aguirre, Taurus, Madrid, 1972.

Libro de los Pasajes, ed. de Rolf Tiedemann, Akal, Madrid, 2005.

Blumenberg, Hans: Las realidades en que vivimos, trad. de Pedro Madrigal, Paidós I.C.E. / U.A.B., Barcelona, 1999.

Salidas de caverna, trad. de José Luis Arántegui, Antonio Machado Libros, Madrid, 2004.

Paradigmas para una metaforología, trad. de Jorge Pérez de Tudela Velasco, Trotta, Madrid, 2003.

La legitimación de la Edad Moderna, trad. de Pedro Madrigal, Pre-Textos, Valencia, 2008.

La inquietud que atraviesa el río, trad. de Jorge Vigil, Península, Barcelona, 2001.

Bueno, Gustavo: "Arquitectura y Filosofía”, en P. Peñalver, F. Giménez, E. Ujaldón (eds.), Filosofía y cuerpo: debates en torno al pensamiento de Gustavo Bueno, Ediciones Libertarias, Madrid, 2005, pp. 405-481.

"Teoría general de la ciudad" en Abaco 6 (Primavera 1989), pp. 37-48.

Cristina Pereira, Paula (org.): A Filosofia e a Cidade, Campo das Letras, Porto, 2008.

(org.): A Filosofia e a Cidade, Vol. II, Edições Afrontamento, Porto, 2010.

Descartes, René: Discurso del método, trad. de Risieri Frondizi, Alianza Editorial, Madrid, 1995.

Donoso Cortés, Juan: Ensayo sobre el catolicismo, el liberalismo y el socialismo, Editora Nacional, Madrid, 1978.

Echeverría, Javier: Telépolis, Destino, Barcelona, 1994.

Cosmopolitas domésticos, Anagrama, Barcelona, 1995;

Los señores del aire: Telépolis y el tercer entorno, Destino, Barcelona, 1999.

Eikasía. Revista de Filosofía, Número 52, Noviembre 2013 (http://revistadefilosofia.com/numero52.htm). 
Fustel de Coulanges, Numa Denys: La ciudad antigua. Estudio sobre el culto, el derecho y las instituciones de Grecia y Roma, trad. de José Manuel Villalaz, Porrúa, México, 1998.

Gilson, Étienne: Las metamorfosis de la Ciudad de Dios, trad. de Antonia García Sánchez, Rialp, Madrid, 1965.

Glotz, Gustave: La cité grecque, La Renaissance du livre, París, 1928.

Gómez Pin, Víctor: El drama de la ciudad ideal. El nacimiento de Hegel en Platón, Taurus, Madrid, 1974.

Granja Castro, Dulce María; Leyva Martínez, Gustavo (eds.): Cosmopolitismo. Democracia en la era de la globalización, Anthropos Editorial, Barcelona, 2009.

Heidegger, Martin: “PPor qué permanecemos en la provincia?”, en De la experiencia del pensar y otros escritos afines, trad. de Jorge Rodríguez, Ediciones del Departamento de Filosofía de la Universidad de Chile, Santiago, 1983.

Kant, Immanuel: Crítica de la razón pura, trad. de Pedro Ribas, Alfaguara, Madrid, 2000.

Lefevbre, Henri: El derecho a la ciudad, trad. de Javier González-Pueyo, Península, Barcelona, 1978.

De lo rural a lo urbano, trad. de Javier González-Pueyo, Península, Barcelona, 1978.

Litoral. Revista de la Poesía, el Arte y el Pensamiento, 244, 2007.

McLuhan, Marshall y Powers, B. R.: La aldea global, trad. de Claudia Ferrari, Gedisa, Barcelona, 1993.

Meagher, Sharon M. (ed.): Philosophy and the City: Classic to Contemporary Writings, State University of New York Press, Albany, 2008.

Mumford, Lewis: La ciudad en la historia: sus orígenes, transformaciones y perspectivas, trad. de Enrique Luis Revol y Javier Rodríguez Hidalgo, Pepitas de Calabaza, Logroño, 2012.

Nestle, Wilhelm: Historia del espíritu griego, trad. de Manuel Sacristán, Ariel, Barcelona, 1975.

Paci, Enzo: Il filosofo e la città: Platone, Whitehead, Husserl, Marx, a cura di S. Veca, Il Saggiatore, Milano, 1979.

Pirenne, Henri: Historia económica y social de la Edad Media, trad. de Salvador Echavarría, FCE, México, 1976.

Las ciudades de la Edad Media, trad. de Francisco Calvo Serraller, Alianza, Madrid, 1972.

Platón: Diálogos, vol. I, traducción de J. Calonge Ruiz, Emilio Lledó, y Carlos García Gual, Biblioteca Clásica Gredos, Madrid, 1981.

Plotino: Vida de Plotino. Eneadas I-II, trad. de Jesús Igal, Biblioteca Clásica Gredos, Madrid, 1982.

Racionero, Luis: El Mediterráneo y los bárbaros del Norte, Plaza \& Janés, Barcelona, 1996. 
Simmel, Georg: "La metrópolis y la vida mental", en M. Bassols, R. Donoso et al. (coomps.), Antología de sociología urbana, UNAM, México, 1988, pp. 47-61.

Sloterdijk, Peter: Esferas II. Globos, trad. de Isidoro Reguera, Siruela, Madrid, 2004.

Spengler, Oswald: La decadencia de Occidente, vol. II, trad. de Manuel García Morente, Espasa Libros, Madrid, 1998.

Torres Tovar, Carlos Alberto; Viviescas Monsalve, Fernando y Pérez Hernández, Edmundo: La ciudad: hábitat de diversidad y complejidad, Universidad Nacional de Colombia, Bogotá, 2000.

Tovar, Antonio: Vida de Sócrates, Alianza, Madrid, 1984.

Toynbee, Arnold: Ciudades en marcha. Alianza Editorial, "Biblioteca Fundamental de Nuestro Tiempo", Madrid, 1984.

Trias, Eugenio: El artista y la ciudad, Anagrama, Barcelona, 1976.

Tucídides: Historia de la Guerra del Peloponeso, trad. de Antonio Guzmán Guerra, Alianza Editorial, Madrid, 1989.

Vico, Giambattista: Principios de ciencia nueva, 2 vols, trad. de J. M. Bermudo y Assumpta Camps, Ediciones Folio, Barcelona, 2002.

Weber, Max: Economía y sociedad. Esbozo de sociología comprensiva, trad. de José Medina Echavarría, FCE, México, 1964, vol. II. p. 938 ss.

La ciudad occidental y la oriental, en M. Bassols, R. Donoso et al. (coomps.), Antología de sociología urbana, UNAM, México, 1988, pp. 63-75.

Wittgenstein, Ludwig: Aforismos. Cultura y valor, trad. de Elsa Cecilia Frost, Espasa Calpe, Madrid, 1996.

THÉMATA. Revista de Filosofía, №51 enero-junio (2015) pp.: 145-167 doi: 10.12795/themata.2015.i51.08 
